\title{
CYCLIC TESTING OF A BRICK WALL STRENGTHENED WITH A PLASTER
}

\author{
COATING OF GLASS REINFORCED CEMENT
}

\author{
D L Hutchison* and P M F Yong*
}

\section{ABSTRACT:}

A $2.000 \mathrm{~m}$ long by $2.400 \mathrm{~m}$ high brick wall was coated on both sides with a $14 \mathrm{~mm}$ thickness of glass reinforced cement (GRC) and tested by cyclic loading applied as in-plane shear. Additional reinforcement at wall ends served to ensure a shear mode of failure in the wall and the enhancement of total strength resulting from this reinforcement was determined by finite element analysis. Although the wall demonstrated only limited ductile characteristics, the consistency of maximum strength obtained during cycling in this range was note-worthy. The cost of the GRC coating was estimated, and a value of dependable shear strength is recommended. for walls of aspect ratio less than 0.5 .

\section{INTRODUCTION:}

A series of tests simulating earthquake loading applied as cyclic in-plane loading to brick walls strengthened by various methods is continuing at MWD Central Laboratories. Strengthening solutions considered so far are:

- vertical post-tensioning

- reinforced sprayed concrete (150 $\mathrm{mm}$ thick applied to one face)

- Ferro-cement (mortar plus mesh $10 \mathrm{~mm}$ thick plastered to both faces)

- glass reinforced cement (GRC) (20 $\mathrm{mm}$ thick plastered to both brick faces).

Preparation of a wall with a plastered surface of steel fibre-reinforced concrete (FRC) is under way. Results of the various strengthening methods will be compared upon completion of the series.

It is believed that most of the strengthening solutions described above are particularly applicable to squat walls, that is, walls where the dominant means of resistance is internal shear, rather than flexure. The situation of walls with high bending stresses requires special treatment in the form of large diameter vertical bars at ends which could not easily be harmonised from an architectural or structural point of view with the thin spray-on or plaster coating which forms the strengthening solution.

However tests by Thurston (9) showed that GRC could be used to strengthen "slender" walls that fail in flexure rather than shear. He used dry stacked masonry walls (i.e., no mortar) with $6 \mathrm{~mm}$ of heavily glassed GRC on both faces of walls with aspect ratio 0.83 . Linear narrow elastic hysteresis loops were developed up to a failure load corresponding to a flexural

* Ministry of Works and Development, Wellington modulus of rupture of $13.4 \mathrm{MPa}$ and an effective elastic modulus of GRC of $13.46 \mathrm{GPa}$. The brittle flexural failure mode was attributed to the GRC being "overglassed" but would also have been influenced by the absence of flexural reinforcement at wall ends. Subsequent out of plane loading tests provided similar GRC rupture strength.

In this paper, preparation and testing of the wall strengthened by GRC coatings is described.

\section{DESCRIPTION OF TEST UNIT}

\subsection{Wall Dimensions}

The size of the test wall was such that the effective aspect ratio $h_{w} / l_{w}$ is less than 1.0, where $h_{w}=$ height of the wall from the point of contraflexure, $l_{w}=$ horizontal length of the wall. The dimension of the wall is nominally $2400 \mathrm{~mm}$ high and $2300 \mathrm{~mm}$ long, giving an effective aspect ratio of 0.52 since the wall will be loaded in double curvature. Hence the wall falls into the category of "Cantilevered Shear Walls of Limited Ductility" in accordance with the draft Amendment A3 to the Loadings Code NZS4203:1976 (which will be circulated shortly for public comment).

\subsection{Wall Construction}

Figure 1 shows the full construction details of the wall. The wall was constructed on a reinforced concrete foundation beam used in a previous Central Laboratories project and had a reinforced concrete capping beam mortared in position on top. $16 \mathrm{~mm}$ holes were drilled in these beams and DHI0 bars (where DH denotes deformed, high yield grade 380 bars; 10 indicates the diameter of the bar in $\mathrm{mm}$ ) acting as dowels were epoxyed into place using the commercial epoxy resin "Expocrete $S^{\pi}$.

In order to suppress flexural failure of the wall, two concrete columns of dimension $165 \times 115 \mathrm{~mm}$, each containing $2 / \mathrm{DH} 20$ bars were constructed at the ends 

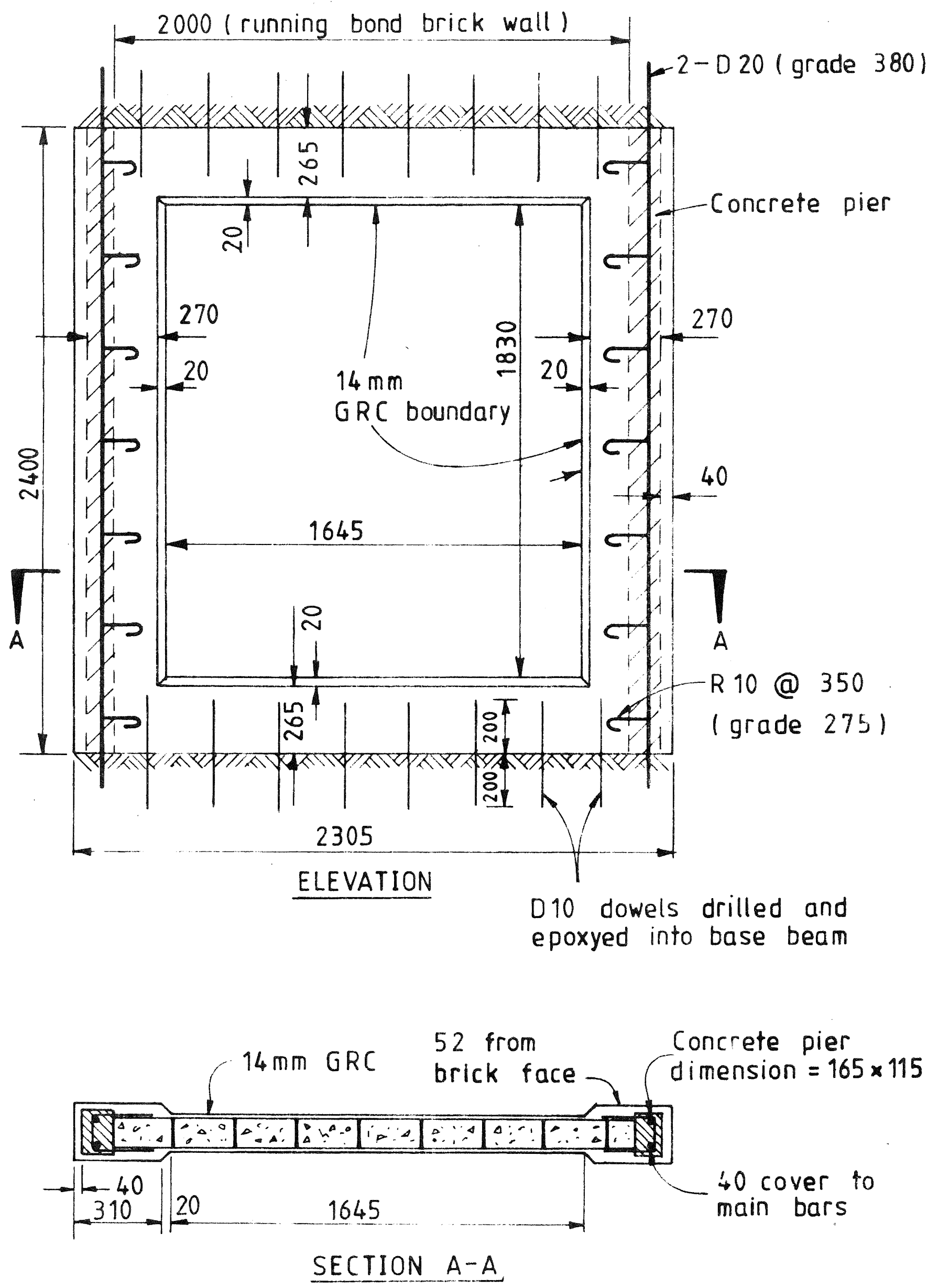

FIG. 1 DETAILS OF UNIT SWL GRC WALL 
of the wall. Rl0 stirrups at $350 \mathrm{~mm}$ centres were provided to facilitate transfer of shear between the GRC coating and the columns.

The application of glass reinforced concrete (GRC) was intended primarily to provide shear carrying capacity to the brick wall. Over the brick panel the thickness of the GRC was limited to $14 \mathrm{~mm}$ and at the ends of the wall and over the dowels the GRC was locally thickened as shown in Figure 1. The thickening was intended to provide anchorage to the $14 \mathrm{~mm}$ GRC layer over the brick wall.

The GRC was designed and mixed by the concrete section of Central Laboratories and the application of the GRC to the faces of the brick wall was carried out by a Tradesman Plasterer.

\section{PROPERTIES OF MATERIALS:}

\subsection{Reinforcing Steel}

Table 1 gives the properties of the reinforcing steel used in the test wall.

\section{$3.2 \quad$ Brickwork}

Huntly H3O firebricks (dimension $230 \times 115 \times 75 \mathrm{~mm}$ ) were used for building the wall as these were the most readily obtainable solid bricks. The mortar used consisted of 1 part lime : 1 part cement : 4 parts sand by weight.

This was as weak a mix as could be worked and was arrived at by trial and error. It approximates the mix 5 parts sand : I part lime : 1 part cement, stipulated in a specification in use in $1910(3)$.

Table $2(a)$ and $2(b)$ show results of direct shear and tension tests on the brickwork. While there is considerable scatter, it is clear that the contribution of brick strength is negligible when compared to a value of dependable shear strength of the strengthened wall of $0.8 \mathrm{MPa}$ (based on gross cross-section), later proposed in this paper. This will be the case of many old buildings where, even though the mortar may have a reasonable cement content, bond with the brick has been lost.

Table 2 (c) gives compressive strength of mortar cylinders. The average of the three batches is $4.3 \mathrm{MPa}$.

\section{$3.3 \quad$ GRC}

\section{i) General}

Figure 2 shows the form of the loaddeflection relationship for GRC loaded in flexure. (1) The difference between "proportional limit" (A) and "ultimate strength" (B) depends upon the amount, length and orientation of fibres. The maximum load is controlled primarily by fibres gradually pulling out and hence the total energy absorbed (or "toughness") as measured by the area under the load deflection curve before complete separation is at least 10-40 times higher for fibre reinforced concrete than for plain concrete. Volume percentage of fibres and fibre aspect ratio strongly influence the maximum load. (1) The optimum fibre content is controlled in practice by the need to avoid "balling" of the fibres during mixing. Application of GRC is frequently by "spray-up" where chopped glass fibre and cement slurry are simultaneously deposited into a form and hence mixed at the point of placement. However, while this gives satisfactory results for an essentially "down-hand" spray operation, it is not considered suitable for spraying vertical faces because of the loss of the free fibre falling to the ground. Application of a premix must be used here.

\section{ii) Mix Used in the Present Tests}

One of the aspects detracting from the use of GRC in situations where strength is important is the observed loss of strength with time. (5) This is commonly believed to be the result of attack of the highly alkaline cement environment on the glass fibres. While alkali-resistant fibres are now available and almost universally used, their development has been relatively recent and sufficient time has not yet elapsed to prove from real-time tests when that rate of loss of strength tends to zero. Estimated long-term properties of "typical spraydewatered GRC" where five percent by weight of Pilkington's Cem-Fil AR (Alkali-Resistant) glass fibre is used show a $19 \%$ decrease in in-plane shear under dry conditions. (5) Reference(10), however, cites test results gained over a ten year period which indicate a negligible loss in strength of GRC in a dry environment.

The effect of the alkaline environment on the glass fibres may, in fact, be a physical as well as a chemical problem. (2) It is possible that the growth of crystals of cement hydrate around the fibres is damaging them. There may therefore be advantage in minimising the free space within the cement paste. Partly for this reason, it was decided to use an acrylic emulsion base in the preparation of the GRC mix. A product "MC-76" supplied by Rohm and Haas was added in the proportion of $15 \%$ by weight of cement. Because acrylic emulsions tend to produce considerable foam during the mixing operation, 1\% of "Bevaloid 682" manufactured by Bevaloid Chemicals, Levin, was added per unit weight of acrylic emulsion.

The use of acrylic emulsion has the added advantage that moist curing of the GRC is not required because of the sealing effect obtained at free surfaces. The acrylic emulsion also enhances the bond of glass fibres to surrounding cement paste through producing an interface film on the fibre surfaces. Finally, adhesion between the cement paste and substrate (the brick wall in this case) is improved.

Table 3(a) details the mix used. The GRC fibres were added last to the mortar, being fed through the fingers to ensure there was no balling. The paddles of the mixer were kept rotating during this operation and for another 30 seconds or so after the 


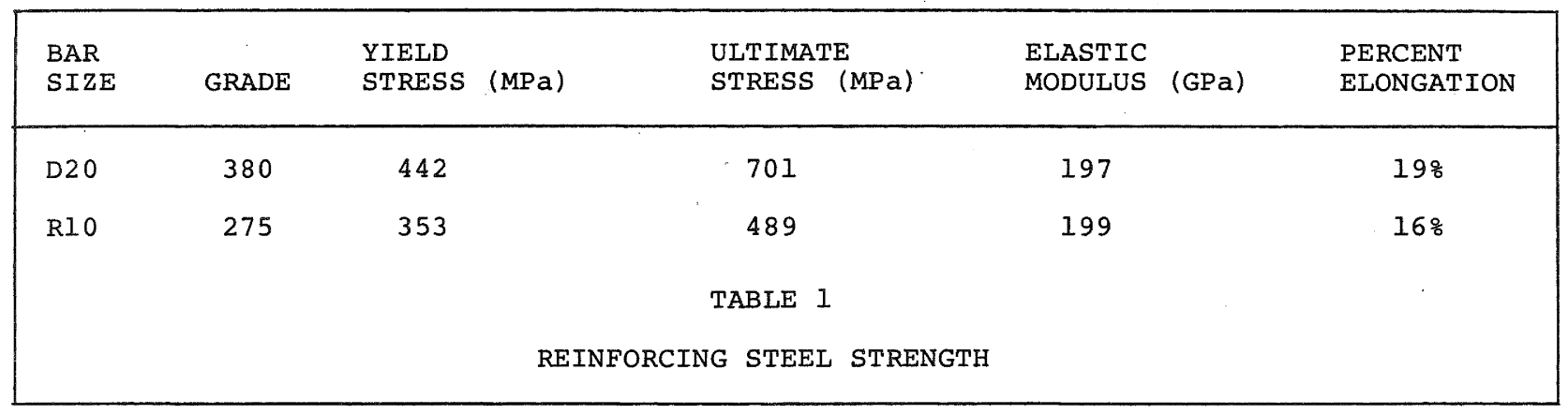

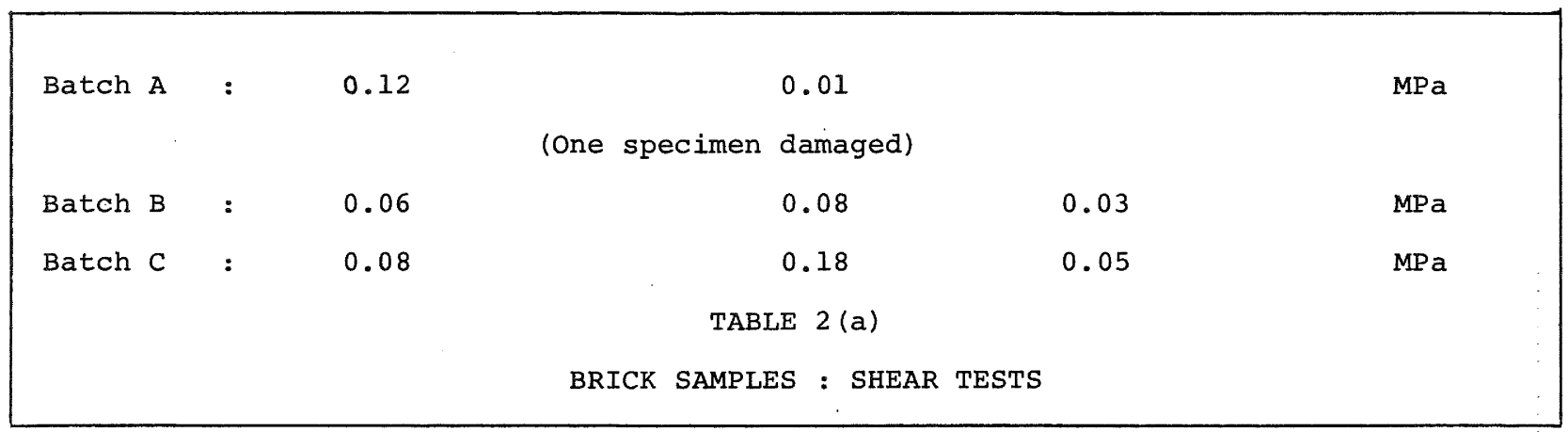

\begin{tabular}{|cccccc|}
\hline Batch A & $:$ & 0.03 & 0.02 & 0.06 & $\mathrm{MPa}$ \\
Batch B & $:$ & 0.02 & 0.01 & 0.06 & $\mathrm{MPa}$ \\
Batch C & $:$ & 0.002 & 0.01 & 0.01 & $\mathrm{MPa}$ \\
& \multicolumn{3}{c}{ TABLE 2(b) } \\
& BRICK SAMPLES : TENSILE TESTS & \\
\hline
\end{tabular}

\begin{tabular}{|c|c|c|c|c|c|}
\hline Batch A & : & 4.30 & 3.95 & 4.15 & $\mathrm{MPa}$ \\
\hline Batch B & : & 5.04 & 4.63 & 4.81 & MPa \\
\hline Batch C & : & 4.05 & 4.02 & 4.13 & MPa \\
\hline \multicolumn{6}{|c|}{ TABLE $2(c)$} \\
\hline \multicolumn{6}{|c|}{ MORTAR CYLINDERS : COMPRESSION TESTS } \\
\hline
\end{tabular}

$10 \mathrm{~kg}$ Cement
$5 \mathrm{~kg}$ Sand (passing $1 \mathrm{~mm}$ )
$1 \mathrm{~kg}$ Hydrated Lime
$0.7 \mathrm{~kg}$ Cem-Fil 660 glass
(Chopped to $20 \mathrm{~mm}$ length)
$1.5 \mathrm{~kg}$ Acrylic Emulsion "MC-76"
$15 \mathrm{gm}$ Defoamer "Bevaloid $682 "$
Water to suit plasterer (about $3 \mathrm{~kg}$ )
TABLE $3($ a)
GRC MIX DESIGN




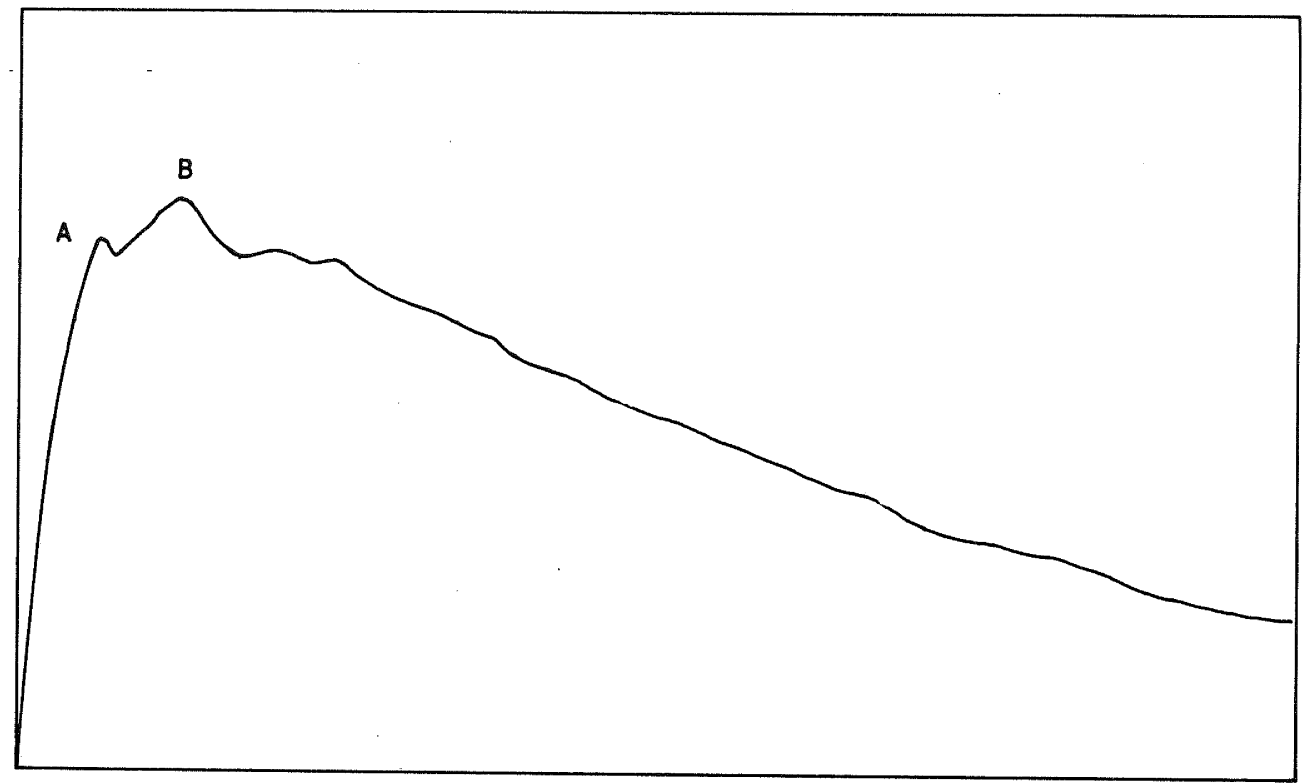

FIG. 2 SCHEMATIC LOAD DEFLECTION DIAGRAM FOR GRC

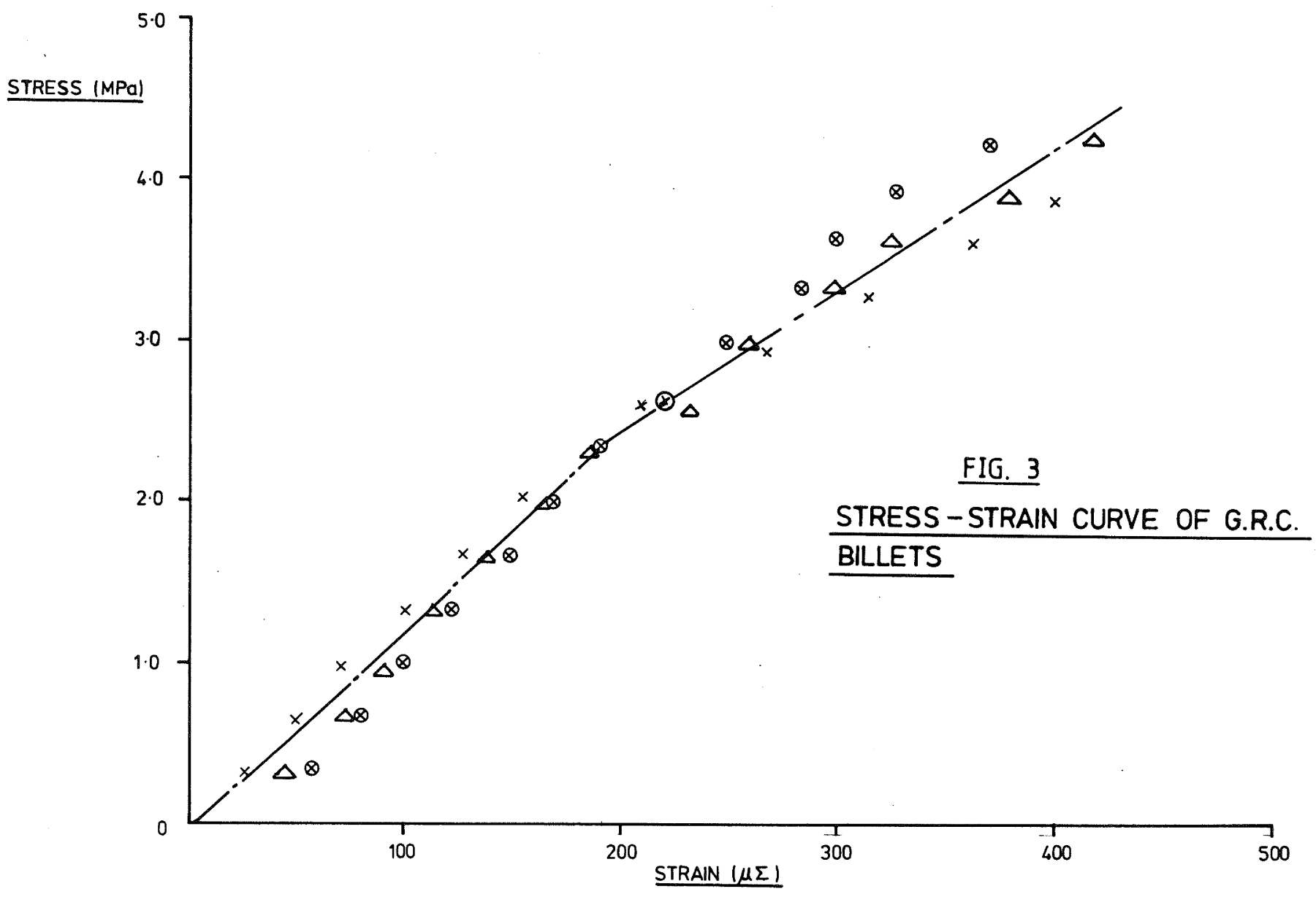


addition of GRC was completed and the mixture appeared homogenous. Figure 3 shows results of tensile tests on three $60 \mathrm{~mm}$ wide by $10 \mathrm{~mm}$ thick specimens, and average values from these plots are presented in Table $3(\mathrm{~b})$. The tensile tests were carried out in a universal testing machine with the strain measured using vibrating wire gauges of gauge length $135 \mathrm{~mm}$.

\section{TEST PROCEDURE:}

The test unit was subjected to double curvature loading using a loading system developed in a previous central Laboratories project. (6) Figure 4 shows the general view of the loading and reaction system. Throughout the test, the wall was subjected to a deflection control test sequence, as follows :

1 cycle $\pm 1.0 \mathrm{~mm}$

2 cycles $\pm 2.0 \mathrm{~mm}$

4 cycles $\pm 4.0 \mathrm{~mm}$

2 cycles $\pm 6 \mathrm{~mm}$ nominal

2 cycles $\pm 8 \mathrm{~mm}$ nominal

\section{TEST RESULTS:}

Figure 5 shows the load-deflection hysteresis loops. Figure 6 shows the test unit at the stages indicated on Figure 5. At $2 \mathrm{~mm}$ deflection a ratio of mid-height to top deflection in excess of 0.4 is obtained, indicating that the wall is behaving in a reasonably symmetrical manner. At the attainment of peak load, at about $3.7 \mathrm{~mm}$ deflection, this ratio is down to 0.35 indicating greater flexibility of the top half, probably due to sliding of the concrete beam relative to the coated brick work. This is well developed at the nominal $8 \mathrm{~mm}$ maximum deflection when the above ratio is about 0.13 .

In the cycles up to $+2 \mathrm{~mm}$ deflection at the top of the wall, the wall maintained its stiffness. The peak loads attained both in the push and the pull cycles at this deflection were about $350 \mathrm{kN}$. No cracking was observed in the wall.

At the first cycle of $4 \mathrm{~mm}$, the peak loads attained both in pushing and pulling were $450 \mathrm{kN}$. First cracking was noted at cycle 1 of pull loading at $4 \mathrm{~mm}$, this occurred in the $14 \mathrm{~mm}$ GRC zone in the form of diagonal disjointed hairline cracks. Subsequent cycles at $4 \mathrm{~mm}$ resulted in a progressive decline in stiffness and the peak load attained, more so in the push cycle.

Further loading up to nominal $+6 \mathrm{~mm}$ resulted in more diagonal crack development in the $14 \mathrm{~mm}$ GRC zone. The stiffness degraded markedly in these cycles. The maximum crack width in the $14 \mathrm{~mm}$ GRC zone was $1.5 \mathrm{~mm}$ in the first pull cycle of $6 \mathrm{~mm}$ deflection. This maximum crack width increased to $4 \mathrm{~mm}$ during the second pull cycle.

A drastic drop in load capacity occurred during the first pull cycle at $8 \mathrm{~mm}$.
This was associated with the sudden development of a major diagonal crack in the wall. The test was terminated at this stage.

\section{FINITE ELEMENT ANALYSIS:}

One face of the wall was modelled using rectangular finite elements and the ICES STRUDL facility available on the MWD IBM 360/168 computer. The purpose of this analysis was mainly to ascertain the proportion of total applied shear load that was transmitted through the $14 \mathrm{~mm}$ coating to brickwork. The results of the tensile tests on GRC described in section 3.3(ii) were used to describe the element properties, and the contribution of brickwork was ignored.

Figure 7 (a) shows the element grid and, superimposed on this, the contours of maximum tensile stress at the onset of tensile failure of a significant number of elements covering the brickwork (the area enclosed by contour J). The total shear load applied to the wall capping beam at this point is $131 \mathrm{kN}$. Figure $7(\mathrm{~b})$ shows the contours of maximum shear stress sustained at this loading. From associated printout (not reproduced here), the shear force on each $0.014 \times 0.200 \mathrm{~m}$ element horizontal cross-section can be obtained and summed. A total load of $105 \mathrm{kN}$ or $80 \%$ of the applied load is sustained by both $14 \mathrm{~mm}$ GRC plates at mid-height of wall with the remainder being carried by the end columns. This reduces to $96 \mathrm{kN}$ or $73 \%$ at $200 \mathrm{~mm}$ from transition to bottom beam whereas $111 \mathrm{kN}$ (85\%) is transferred directly into the top layer of $14 \mathrm{~mm}$ GRC. The mid-height factor of $80 \%$ is used subsequently (section 7) in determining a proposed design load for GRC.

The maximum principal tensile stress predicted (Fig $6(a)$ ) is $2.45 \mathrm{MPa}$. This is of more interest than internal shear stress maxima because the test wall finally failed in diagonal tension. However, under an applied load of $105 \mathrm{kN}$ per $1.6 \mathrm{~m}$ length of wall $(65.6 \mathrm{kN} / \mathrm{m})$, the maximum principal tensile stress in a long wall with free vertical edges may vary from that in the model of the wall tested, because of the presence of the vertical edge members and the effect of decreased aspect ratio. Accordingly, models of both $10 \mathrm{~m}$ and $5 \mathrm{~m}$ walls of the same vertical cross-section as the model of the wall tested were loaded with $65.6 \mathrm{kN} / \mathrm{m}$. Location of point of contraflexure at both mid-height and top of wall was considered. The models included stiff vertical spring supports along the base, as limited base rotation would exist in practice and recognition of this is recommended in the modelling of shear walls(li).

Table 4 summarises results and Figure 8 shows stress contours for two of the cases. The edge tensile stress on the $5 \mathrm{~m}$ wall is much higher than the maximum tensile stress in the interior, for the case where point of contraflexure is at top of wall. This suggests that failure will commence by tearing at the edge - a flexural mode - and be progressive. In the case of the $10 \mathrm{~m}$ wall, on the other hand, maximum shear values in the interior 


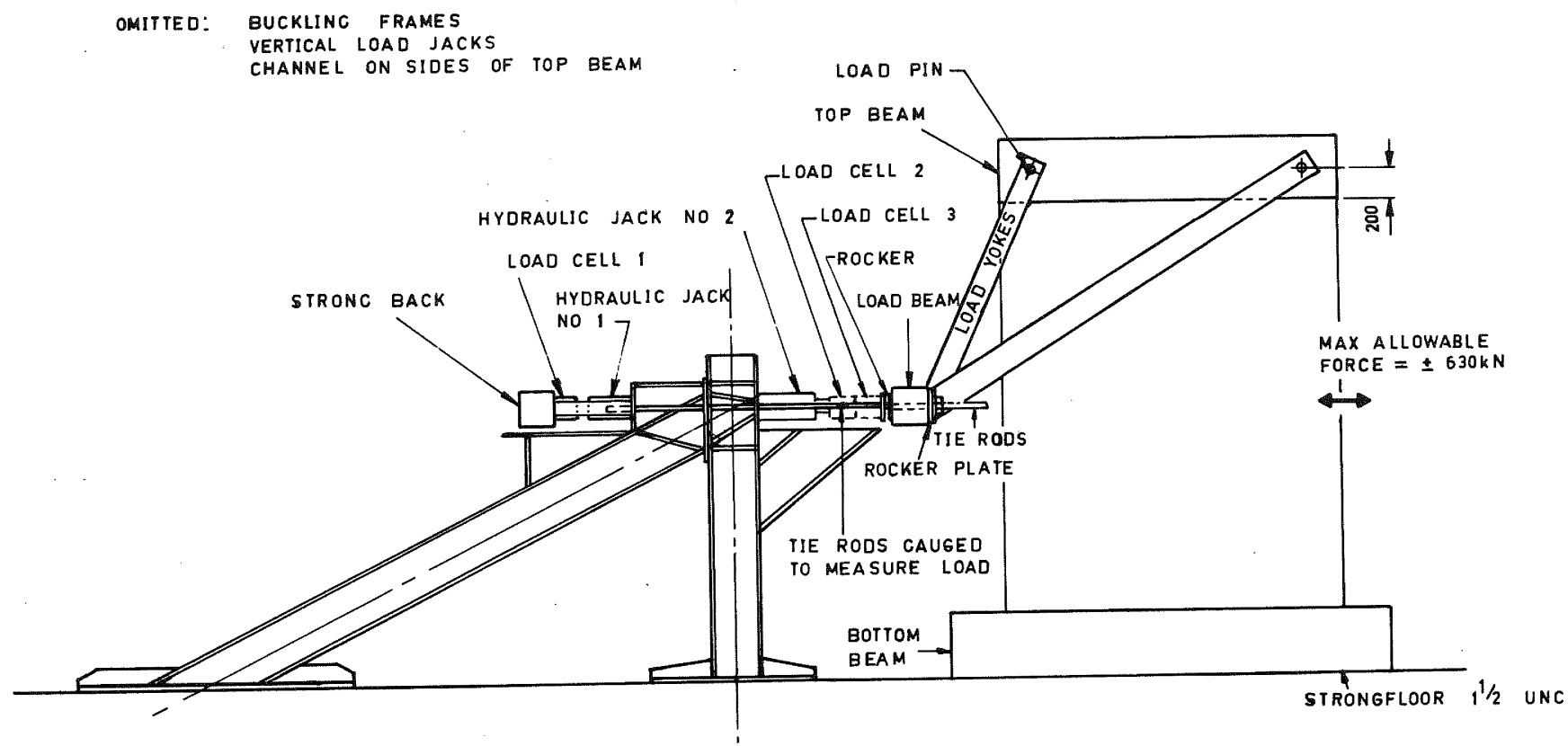

FIG. 4 LOAD-REACTION SYSTEM

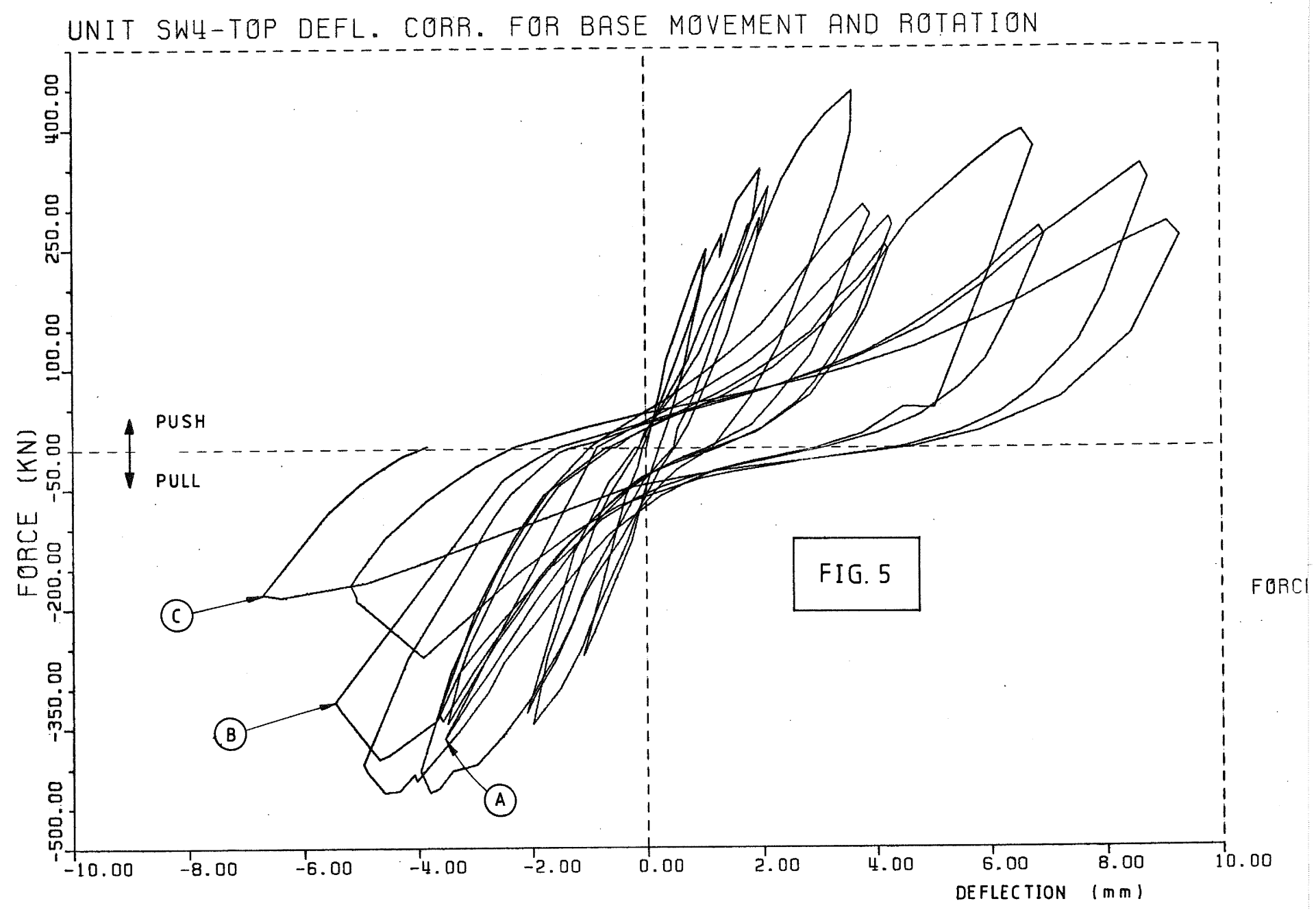




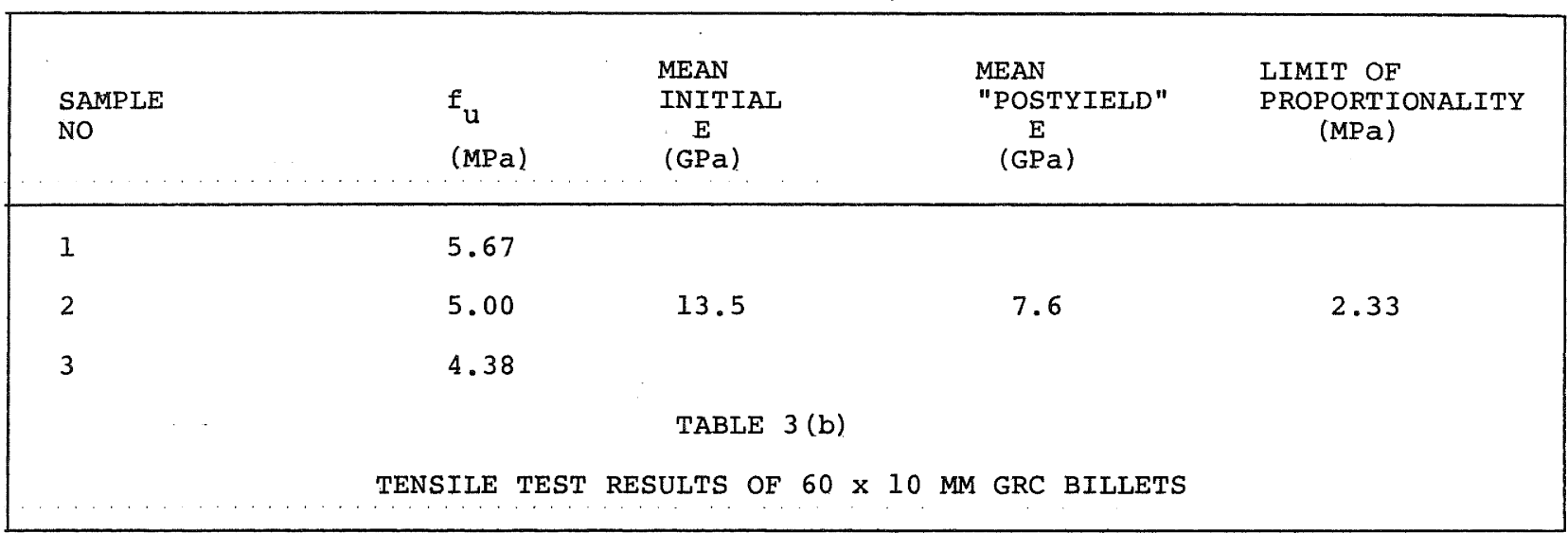

\begin{tabular}{|c|c|c|c|}
\hline \multirow[b]{2}{*}{ 10 Metre Wall: } & \multirow[t]{2}{*}{$\begin{array}{l}\text { Max Shear } \\
\text { (MPa) }\end{array}$} & \multirow[t]{2}{*}{$\begin{array}{l}\text { Max Principal } \\
\text { Stress (MPa) }\end{array}$} & \multirow[t]{2}{*}{$\begin{array}{l}\text { Max Edge } \\
\text { Stress (MPa) }\end{array}$} \\
\hline & & & \\
\hline $\begin{array}{l}\text { - point of contra-flexure } \\
\text { mid-height }\end{array}$ & 3.09 & 3.09 & 1.72 \\
\hline $\begin{array}{l}\text { - point of contra-flexure } \\
\text { top of wall }\end{array}$ & 3.19 & 3.21 & 3.21 \\
\hline \multicolumn{4}{|l|}{5 Metre Wall: } \\
\hline $\begin{array}{l}\text { - point of contra-flexure } \\
\text { mid-height }\end{array}$ & 2.99 & 3.05 & 2.71 \\
\hline $\begin{array}{l}\text { - point of contra-flexure } \\
\text { top of wall }\end{array}$ & 3.08 & 3.19 & 5.74 \\
\hline \multirow[t]{2}{*}{ Model of Tested Wall: } & 2.44 & 2.45 & NA \\
\hline & 4 & & \\
\hline SU & $\begin{array}{l}S \text { OF WALL M } \\
6 \mathrm{kN} / \mathrm{m} / \mathrm{FACE}\end{array}$ & & \\
\hline
\end{tabular}




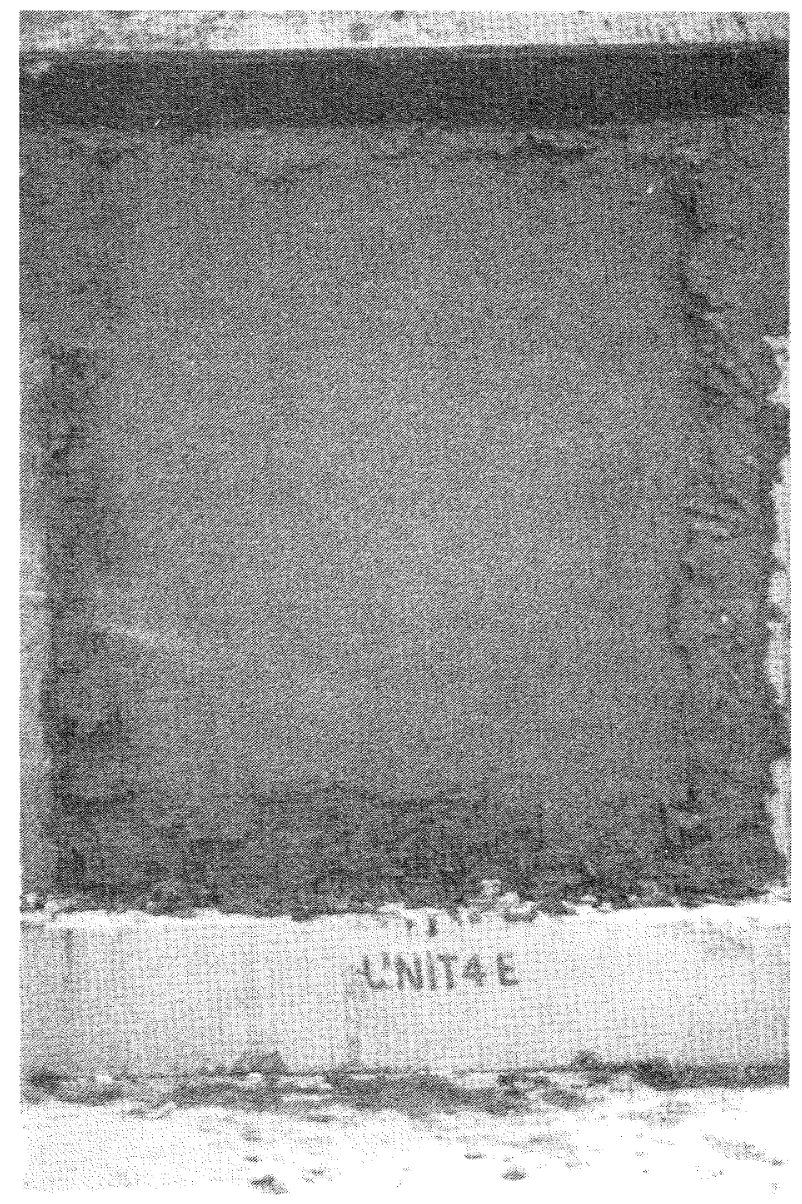

(a) Wall during plastering

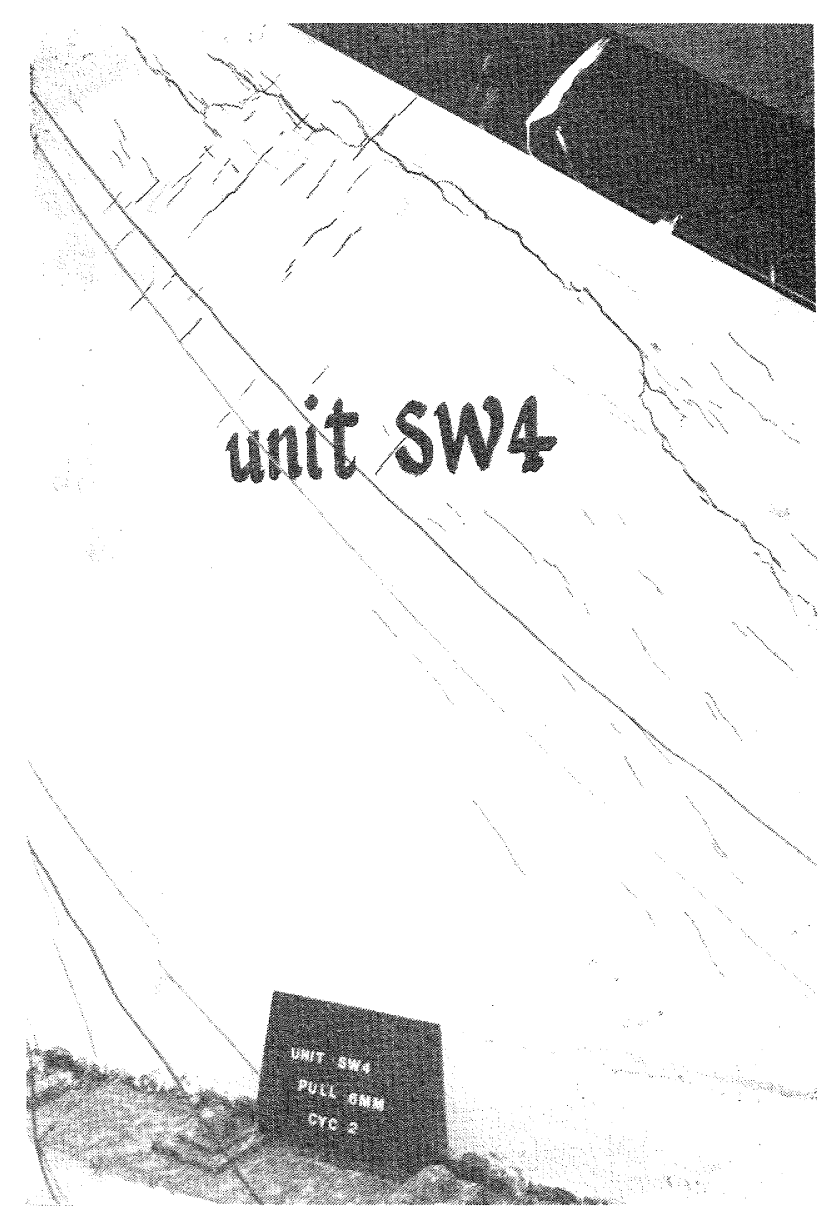

(c) State of test wall corresponding to point B in Fig 5

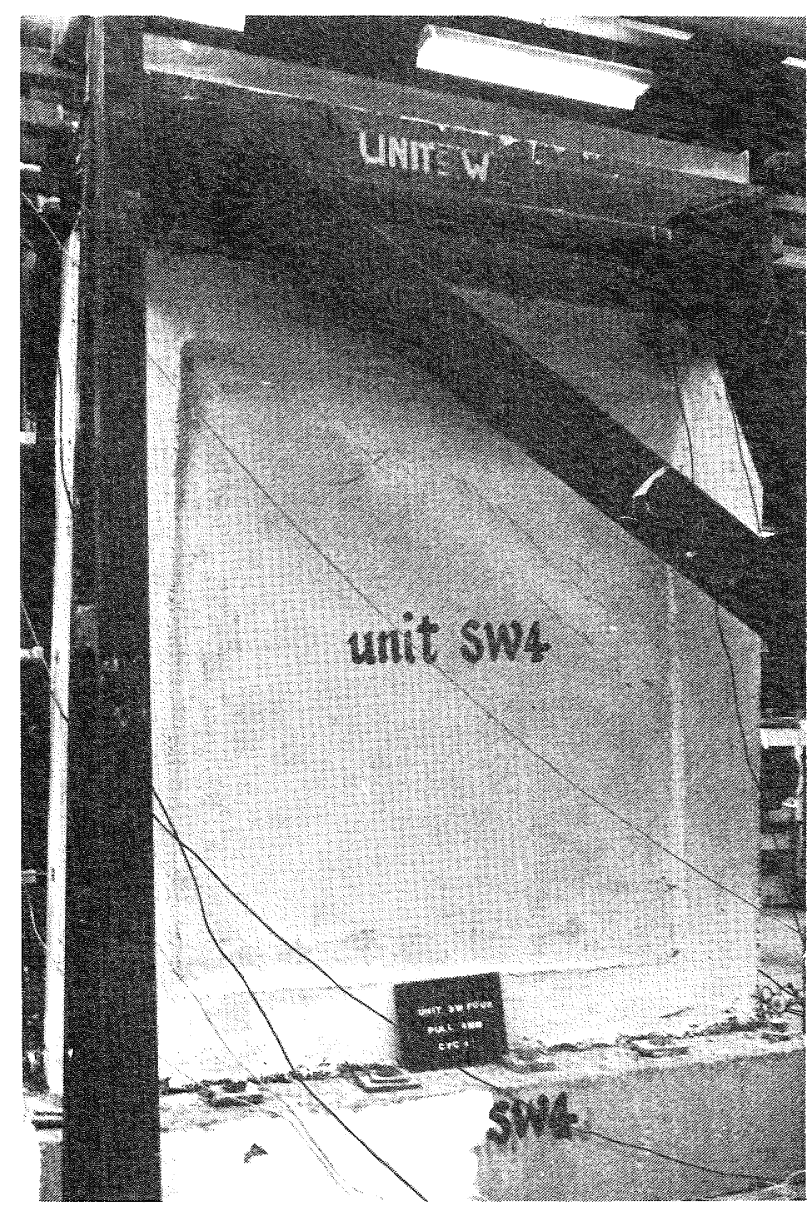

(b) State of test wall corresponding to point $A$ in Fig 5

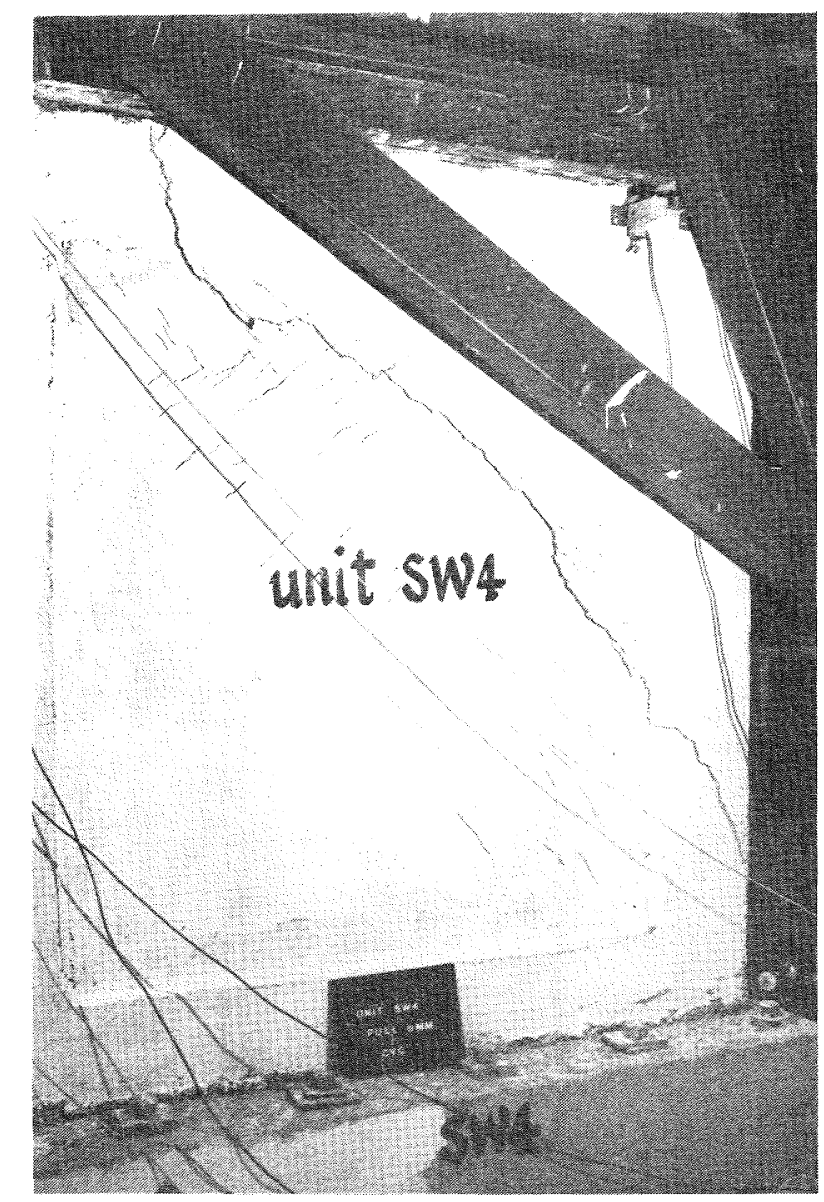

(d) State of test wall corresponding to

FIG. 6 point $C$ in Fig 5 


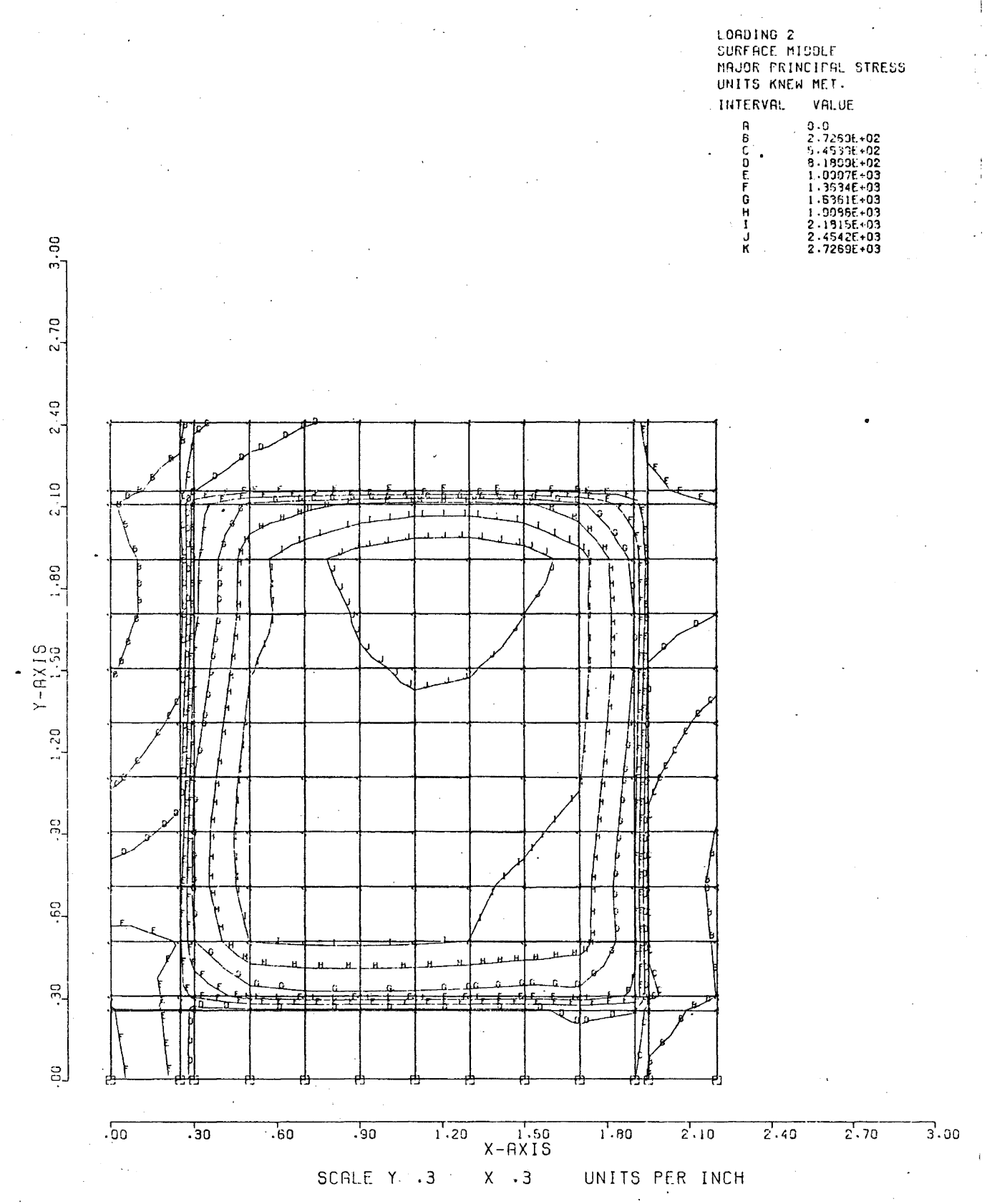

FIG. 7 (a) MAXIMUM TENSILE STRESS IN TEST UNIT
1 orionso 2

MFXTMUM SHEGR STRECO

UHITS KNES MET.

INTERVAL. VALLUE

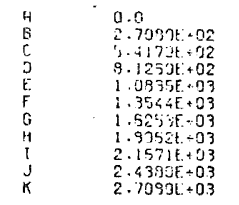

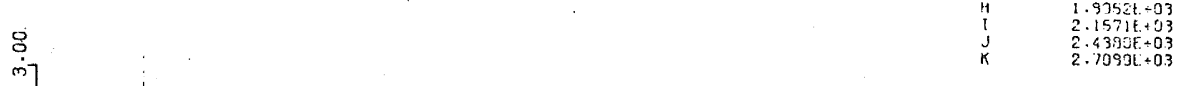

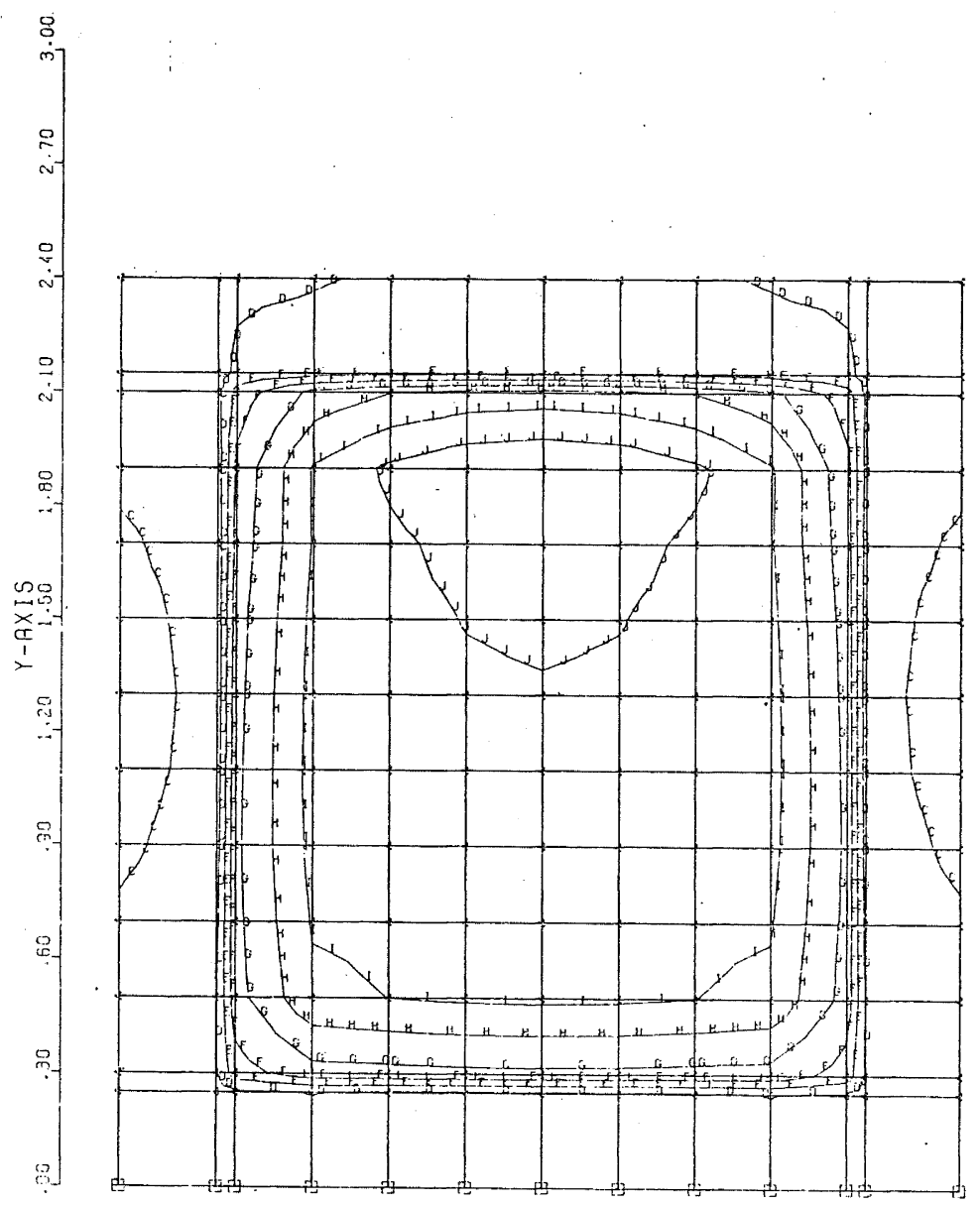

.00

.30

.50 SCF! $Y=Y \quad Y \quad Y=3$

FIG. 7 (b) MAXIMUM SHEAR STRESS IN TEST UNIT

\section{.}

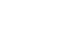

. 
of the wall do not exceed those at the edge.

At this stage of development, therefore, it is recommended that walls with aspect ratio (measured with respect to the point of contraflexure) of more than

$$
2.4 / 5.0=0.5 \text {, say }
$$

should not be designed for strengthening with GRC coating, without the addition of vertical end reinforcement.

A maximum principal tensile stress of about $3.2 \mathrm{MPa}$ is apparent from Table 4, for the $10 \mathrm{~m}$ wall. On the other hand, a maximum tensile stress of only $2.45 \mathrm{MPa}$ is predicted for the model of the wall tested. The design load deduced from the wall tests must be reduced by a factor of :

$$
2.45 / 3.2=0.77
$$

- in recognition of the greater tensile stresses predicted in long walls.

A further reduction to account for loss of strength with time is not considered necessary because of the dry environment applying to faces of interior walls.

\section{DISCUSSION:}

\subsection{Preparation and Application of GRC}

In practice, large areas of wall may require to be coated with GRC. In such a situation application by a plasterer becomes uneconomic. A spraying device that incorporates a mixing unit and sprays the GRC mix from a nozzle is desirable here. While moves are afoot to obtain such a device for use in further wall tests, the plasterer did not experience difficulty in applying GRC to the test unit.

\subsection{Recommended Design Load for GRC}

The New Zealand Standard Loadings Code (7) requires that a frame structure "should be capable of deflecting laterally through at least eight load reversals so that the horizontal deflection at the top of the main portion of the building ... is at least four times that at first yield, without the horizontal load carrying capacity of the building being reduced by more than 20 per cent" (Clause C3.2).

For a frame structure, the structural Type Factor (S) is normally 0.8 , and we take Materials Factor $M=1.0$. If we assume that the earthquake which forces eight load reversals (ie, four load cycles) to occur at four times yield displacement is the design earthquake, then, invoking the Equal Displacement Rule, the displacement at the top of the yielding frame structure under the earthquake loading described above is obtained from applying a loading with

$$
\begin{aligned}
\text { SM } & =4 \times(0.8 \times 1.0) \\
& =3.2
\end{aligned}
$$

to an elastically responding model.
If the type of structure is other than a frame, then a consistent definition of adequate ductility would be that the structure not lose more than 20 per cent of its strength if cycled four times to a deflection at the top of the main portion of the structure equal to $3.2 / \mathrm{SM}$ times the calculated deflection under code loading (c $)$. The draft Third Amendment to the Loading Code requires an S-factor of 2.0 for squat shear walls. Let us assume that Materials Factor of 1.0 is appropriate for GRC, then the ratio of "design earthquake" displacement to yield displacement is

$\frac{3.2}{(2.0 \times 1.0)}=1.6$

Finally, let us assume that the hysteresis loops obtained for the test wall are of the same shape as those for a "shear wall of limited ductility", at least in the region where slip at connections does not dominate.

In the case of a test of primary seismic resisting elements of a building, the $20 \%$ loss is increased to $30 \%(7)$. The criterion of not more than a $30 \%$ loss in strength after four cycles was only tested at a displacement of $4 \mathrm{~mm}$. Relative to the peak load obtained at the first cycle, a drop of over $40 \%$ is apparent for the "push" direction of loading (20\% for the "pull" direction). However, the comparison must be made between the loads at the ends of the fourth set of half cycles and the loads at $1 / 1.6$ of this displacement, i.e. at $4 / 1.6=2.5 \mathrm{~mm}$. For both half cycles at $2.5 \mathrm{~mm}$, a load of $350 \mathrm{kN}$ was sustained by the unit; a minimum peak load of $71 \%$ of this load $(248 \mathrm{kN})$ was sustained during the fourth cycle to $\pm 4.0 \mathrm{~mm}$. We therefore propose a "design strength" for the test unit of $350 \mathrm{kN}$ which anticipates the allowed $30 \%$ reduction in strength of a primary seismic resisting element. At this point (see Section 5) slip at connections is not pronounced, and the loss in strength is considered due to onset of tensile yield in the GRC.

The designer of a GRC strengthening scheme for brick walls is not dealing with walls of the same geometry as the test unit, nor with vertical end members in the usual case of squat walls. As discussed in section 6, two reduction factors must be applied - a multiplier of 0.8 and of 0.77 . Finally, the effective load on the $1.6 \mathrm{~m}$ length of GRC must be reduced to a load per metre.

Thus, the design load per unit length of $14 \mathrm{~mm}$ GRC applied to both brick faces is

$350 \times 0.8 \times 0.77 / 1.6$

$=135 \mathrm{kN} / \mathrm{m}$.

There is one further reduction needed to obtain the dependable strength for use by the designer and the reason is as follows :

The tests measure the "overstrength" of the GRC which we have regarded as 


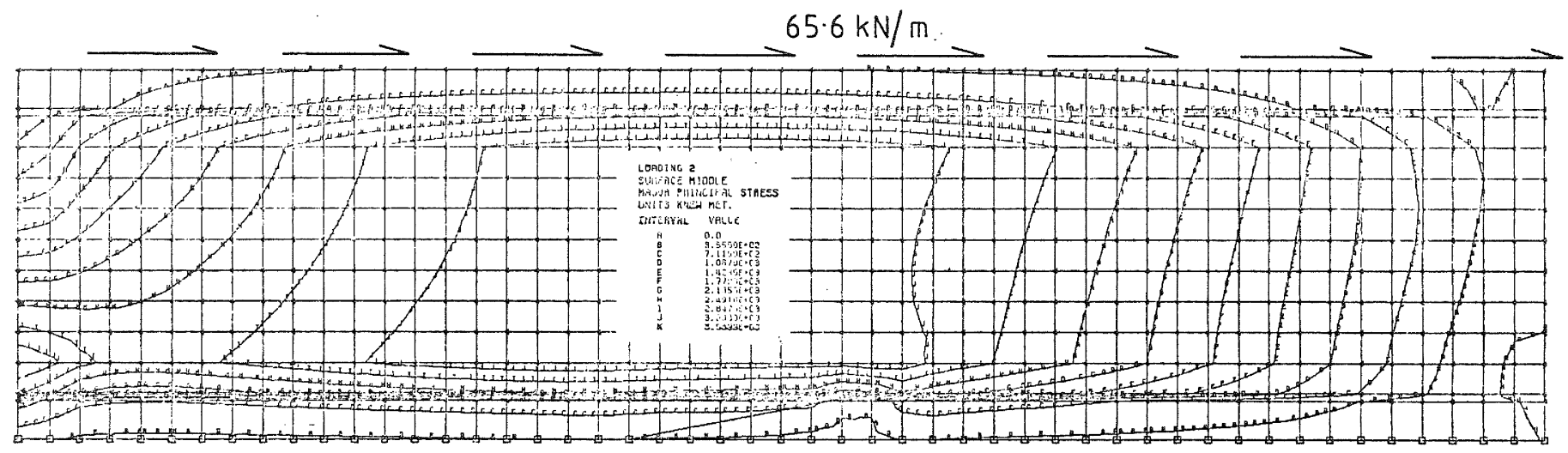
.

50 .60 .20 ?.20

SCALE $Y$ Y $x-A$

UNITS PEA INCH

FIG. 8 (a) COMPUTER MODEL OF 10m WALL WITH ZERO APPLIED MOMENT AT TOP

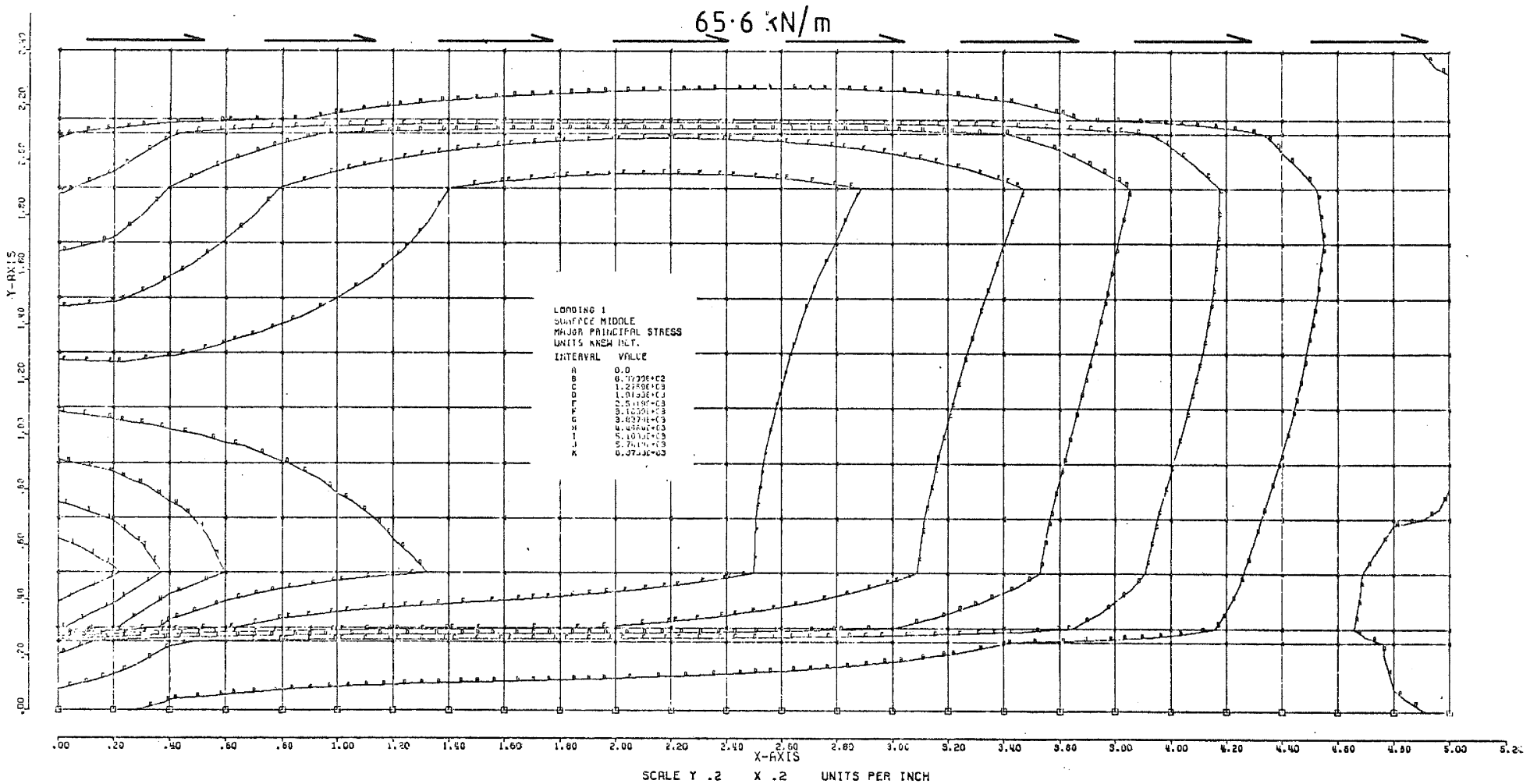

FIG. 8 (b) COMPUTER MODEL OF $5 \mathrm{~m}$ WALL WITH ZERO APPLIED MOMENT AT TOP 
"design strength". However, the Loadings code already contains the assumption that buildings are 50 percent stronger than the dependable strengths equated with the earthquake load case(8). In order to maintain the same level of reserves as is considered to exist in other buildings, the measured strength of the GRC must be reduced for design purposes. At present, there is no New Zealand standard code of practice for GRC design. If we adopt the same $\emptyset$ factor used for shear design of reinforced concrete $(\varnothing=0.85)$ for the design of shear-dominated squat GRC-coated walls, then the measured overstrength should be reduced for design purposes by

$1 /(1.6 \times 0.85)$, ie a factor of 0.78 .

Thus, the dependable strength of the two $14 \mathrm{~mm}$ layers of GRC is

$$
0.78 \times 135
$$

\section{$=105 \mathrm{kN} / \mathrm{m}$}

- or a shear stress on the basis of gross cross-section of GRC of $3.75 \mathrm{MPa}$, for walls of aspect ratio less than 0.5 .

\subsection{Recommended Design Load for Connections}

The design load of $350 \mathrm{kN}$ for the test unit deduced previously is attained at a top displacement of $+2.0 \mathrm{~mm}$. The maximum displacement envisaged under the design earthquake is

$\pm \frac{3.2}{\mathrm{SM}} \times 2.0= \pm 3.2 \mathrm{~mm}$.

However, the hysteresis loops show that a peak load of about $420 \mathrm{kN}$ is attained at that displacement - an increase of $20 \%$. This could rise to $445 \mathrm{kN}$ with further increase in displacement (ie, in size of actual earthquake), but we will assume here that that possibility is sufficiently remote to be ignored.

In order to determine the multiplier which raises GRC design load to the value to be used in design of its connection to horizontal diaphragms, we must reduce the value of $420 \mathrm{kN}$ by multipliers of 0.8 and 0.77 as previously done; and by a divider of 1.6 to obtain load per unit length. The resulting value, $162 \mathrm{kN} / \mathrm{m}$, is then the design load for the connections. This implies an overstrength factor of $162 / 105=1.5$ with respect to dependable strength.

Thus, it is recommended that the dependable strength of the connection to diaphragm be capable of resisting 1.5 times the dependable strength of the GRC when all of this is mobilised by the code load. In the case of a wall loaded to less than dependable strength by the code-prescribed loading $(\mathrm{S}=2.0$ and assuming $M=1.0$ ), then the wall may respond without yielding, and an overstrength factor of $3.2 / \mathrm{SM}=1.6$ should be used for design of connections. This factor is applied to the code-prescribed shear load in the walls.

\subsection{Cost and Ideal Strength of Connectors}

Available costs indicate that about two thirds of the total cost per unit area of strengthening layer is required for connections to diaphragms. Current estimates are as follows:

\section{Connector $\$ 75 /$ metre \\ GRC

$$
\$ 35 / \text { metre }^{2} / \text { face }
$$

For the case where a common connector is not used between top of one wall at one level and bottom of wall above, a total cost of $\$ 234 /$ metre/face results of which $\$ 150$ is for the connector system. Hence it is important that criteria for an economical design be obtained. Although further experimental work is needed, some tentative suggestions can be made from the test results.

The recommended design load per metre per face is, in the case of a wall where dependable strength of GRC is mobilised $162 / 2=81 \mathrm{kN} / \mathrm{m} /$ face.

The wall unit tested had D10 dowels at 200 centres projecting 200 into the GRC. Were these sufficient? Clearly the answer is "No" if we are looking for a full capacity design where minimal slip takes place at the dowels at the time the wall fails. However, if the design load is limited as above, then the shear stress on a dowel is $206 \mathrm{MPa}$ for the configuration used. Assuming that the maximum distortion energy yield criterion applies(12), with a phi factor of 0.9 for steel then the shear in the bar should not exceed

$\frac{275}{\sqrt{3} \times 0.9}=176 \mathrm{MPa}$, which is within 3\% of applied stress. If we now assume, the bearing stress varies linearly over the length of dowel, then the maximum bearing stress is (with phi $=0.7$ )

$\frac{81 \times 10^{3} \times 0.2 \times 2}{10 \times 200 \times 0.7}=23 \mathrm{MPa}$.

This figure may be too high for, although compression tests were not carried out on the GRC, "bearing" failure in this situation is probably initiated by tensile splitting of the GRC along a vertical plane parallel to the direction of the bearing load. Results of the test loading (Section 5) indicates that some slip had taken place at top connectors at an applied load of $420 \mathrm{kN}$ (equivalent to a connector load of $162 \mathrm{kN} / \mathrm{m}$ ) because the ratio of top beam deflection to mid-height wall deflection is as high as 3 at this load. An ideal GRC bearing strength of $15 \mathrm{MPa}$ would be nearer the mark for design of connectors, but this needs to be verified by further tests.

\section{SUGGESTIONS FOR FURTHER WORK:}

i) The ability of the GRC strengthening solution to resist face loading should be tested. It may be necessary to provide additional strength or stiffness to walls by "splinting" particularly where the interstorey height is large. Such a test series would also confirm or otherwise the adequacy of the bond 
between GRC and the brickwork under cyclic loading.

ii) The high proportionate cost of diaphragm/GRC connectors should not be lost sight of. Prediction of strength is difficult and designers would benefit from test data. It is suggested that a series of tests specimens including only the connected length of wall be prepared using various designs and loaded in cyclic shear.

\section{ACKNOWLEDGEMENT:}

The permission of the Commissioner of Works to publish this paper is gratefully acknowledged. The authors are also grateful for the helpful comments of colleagues in the office of the Chief Structural Engineer, and at central Laboratories.

\section{REFERENCES:}

1. A.C.I. Committee 544: 'State-of-theArt Report on Fiber Reinforced Concrete'.

Concrete International Design and Construction. May 1982, Vol. 4, No. 5, pp. 9-30.

2. Clelland, $\mathrm{J}$ : Ministry of Works and Development Central Laboratories. Personal Communication.

3. : Specification of Contract P.W.D. 26941, August 1910.

4. John Young : 'Designing with GRC : A Briefing Guide for Architects'. The Architectural Press, London. 1978.
6. Thurston, S.J. and Hutchison, D.L. : 'Reinforced Masonry Shear Walls : Cyclic Load Tests in Contraflexure'. Bull. NZNSEE, Vol. 15, No. 1. March 1982.

7. for General Structural Design and Design Loadings for Buildings'. NZS 4203. Standards Association of New Zealand.

8. Kelly, T.E. : 'Floor Response of Yielding Structures'. Office of the Chief Structural Engineer, Ministry of Works and Development. Research and Development Report $78 / 1$ September 1978 .

9. Thurston, S.J. : 'Cyclic Racking Tests of Reinforced Concrete Masonry Shear Walls'. Ministry of Works and Development, Central Laboratories Report No. 5-81/8. September 1981.

10. Dixon, J. : 'Glass Reinforced Cement'. Concrete, December 1980.

11. Gill, W.D. : 'Computer Modelling of Shear Walls : Notes for Designers'. Research and Development Report 82/2. Office of the Chief Structural Engineer, Ministry of Works and Development. August 1982.

12. Trahair, N.S. : 'The Behaviour and Design of Steel structures'. Wiley 1977 .

13. Priestley, M.J.N. and Bridgeman, D.O. 'Seismic Resistance of Brick Masonry Walls'. Bull. New Zealand Society for Earthquake Engineering, Vol. 7, No. 4. December 1974.

5. : 'Pilkington Cem-Fil

Alkali-Resistant Glassfibre for Glass Reinforced Cement'. The Kynoch Press, Birmingham B6 7BA, England.

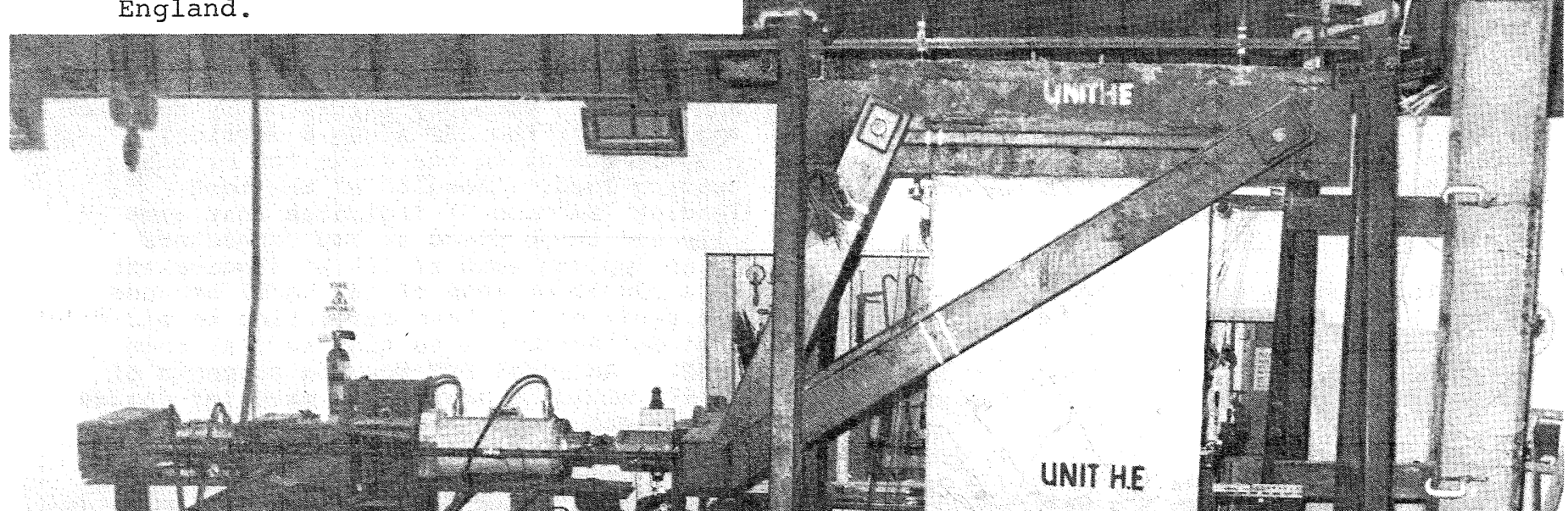

